\title{
HACED ESTO EN MEMORIA MÍA
}

DOI: https://doi.org/10.52039/seminarios.v54i187.547

\author{
ANTONIO BRAVO TISNER ${ }^{1}$
}

El horizonte, bien matizado, que nos presenta el autor sobre la Eucaristía como liturgia de alianza en el AT y como misterio del amor de Jesucristo en el NT, sobre todo en san Pablo, nos ayuda a ubicar dos textos del magisterio reciente: Ecclesia de Eucaristía, Juan Pablo II y Sacramentum Caritatis, Benedicto XVI. La presentación de este ambiente eucarístico viene dado para extraer las consecuencias vocacionales pertinentes: experiencia del don; adoración eucarística como escuela de lo gratuito; servicio a los pobres y excluidos; Iglesia evangelizadora; misión al mundo,... Y para centrar las distintas vocaciones en la Iglesia unas preguntas, ¿Puede haber vocaciones sin escuchar la llamada? ¿Podrá escucharse la llamada sin participar en la Eucaristía? ¿Podrá entenderse la llamada sin adoración eucarística?

Se me ha pedido una reflexión sobre la relación existente entre la Eucaristía y la vocación en general. El tema es amplio y complejo. Puesto que no puede ser tratado de forma exhaustiva en el espacio de un breve artículo, me limitaré a desarrollar algunas sugerencias.

Que la Iglesia viva de la Eucaristía y sea edificada de forma constante por ella ${ }^{2}$, es una evidencia para la fe apostólica. Los miembros de la

\footnotetext{
1 Antonio Bravo Tisner nació en Angües (Huesca) en 1942. Ordenado sacerdote en 1965, pertenece a la Asociación de los sacerdotes del Prado. Entre 1983 y 2001 ha sido responsable general de la Asociación de los sacerdotes del Prado. Profesor de teología y delegado episcopal de evangelización de la diócesis de Madrid. Desde junio de 2003, párroco de San León Magno, en Madrid. Desde 2004 a 2007 delegado episcopal de Cáritas española.

2 La encíclica Ecclesia de Eucaristía arranca con esta afirmación: «La Iglesia vive de la Eucaristía.» El capítulo II lleva por título: la Eucaristía edifica la Iglesia. Juan Pablo II insiste en el « influjo causal de la Eucaristía en los orígenes mismos de la Iglesia» Citando ampliamente la constitución Lumen Gentium, subraya como la Eucaristía es el centro del proceso de crecimiento de la Iglesia: «El Concilio
} 
comunidad de la nueva alianza «acudían asiduamente a la enseñanza de los apóstoles, a la comunión, a la fracción del pan y a las oraciones». (Hch 2, 42) El apóstol Pablo, por su parte, presenta la reunión de la Iglesia para la fracción del pan como un acto de fidelidad al mandato del Señor: «Porque yo recibí del Señor lo que os he transmitido: que el Señor Jesús, la noche en que fue entregado, tomó pan, y después de dar gracias, lo partió y dijo: "Este es mi cuerpo que se da por vosotros; haced esto en recuerdo mío." Asimismo también la copa después de cenar diciendo: "Esta copa es la Nueva Alianza en mi sangre. Cuantas veces la bebiereis, hacedlo en recuerdo mío"». (1Cor 11, 23-25)

Pero sería un error que el mandato del Señor quedase reducido a la repetición del rito sacramental. El «haced esto en memoria mía» ha de entenderse en un sentido amplio y dinámico. La cena pascual de Jesús con sus discípulos fue la culminación de la vida, predicación y misión. La reunión con los Doce para celebrar la nueva alianza en su sangre, estuvo precedida de una intensa actividad: llamó uno a uno a los discípulos, y los fue formando por el camino para este momento decisivo en la historia de la humanidad. En la intimidad sobria del cenáculo se cerraba la etapa de la antigua alianza y empezaba la andadura de los tiempos nuevos. La nueva alianza configuraba de nuevo al pueblo de Dios en la historia, una nueva creación tenía lugar. El muro que separaba a los pueblos irreconciliables fue derribado en la Pascua del Hijo, que la Iglesia no cesa de celebrar en la Eucaristía (cf Ef 2, 14-22).

El pueblo de la alianza es en realidad un pueblo de convocados. "Vosotros sois linaje elegido, sacerdocio real, nación santa, pueblo adquirido, para anunciar las alabanzas de Aquel que os ha llamado de las tinieblas a su admirable luz, vosotros que en un tiempo no erais pueblo y que ahora sois el Pueblo de Dios, de los que antes no se tuvo compasión, pero ahora son compadecidos». (1P 2, 9-10) En el misterio del amor, la Iglesia se une a la pascua del Hijo para convocar y reunir a los hijos de Dios dispersos en un nuevo pueblo (cf. Jn 11, 52). «La Eucaristía es Cristo que se nos entrega, edificándonos continuamente como su cuerpo.» Así se establece «la sugestiva correlación entre la Eucaristía que edifica la Iglesia y la Iglesia

\footnotetext{
Vaticano II ha recordado que la celebración eucarística es el centro del proceso de crecimiento de la Iglesia. En efecto, después de haber dicho que "la Iglesia, o el reino de Cristo presente ya en misterio, crece visiblemente en el mundo por el poder de Dios", como queriendo responder a la pregunta: ¿Cómo crece?, añade: "Cuantas veces se celebra en el altar el sacrificio de la cruz, en el que Cristo, nuestra Pascua, fue inmolado (1Co 5, 7), se realiza la obra de nuestra redención. El sacramento del pan eucarístico significa y al mismo tiempo realiza la unidad de los creyentes, que forman un sólo cuerpo en Cristo (cf. 1Co 10, 17)"». (21)
} 


\section{"HACED ESTO EN MEMORIA MIA", ANTONIO BRAVO}

que hace a su vez la Eucaristía ${ }^{3}$.» El sacramento de la alianza, presupone siempre el pueblo de convocados. Detengámonos un momento en este punto, para pasar luego a precisar los rasgos que configuran la vocación que brota del misterio eucarístico.

\section{La asamblea eucarística}

El pueblo de la alianza se reúne siempre bajo la iniciativa divina. El culto de Israel, de la asamblea del desierto, arrancaba siempre de la iniciativa divina. El pueblo hacía en él memoria de su origen e identidad, proyectándose hacia el futuro en la esperanza. Y esta dinámica es la que marca también el culto de la Iglesia, el «Israel de Dios» (Gal 6, 16). La Eucaristía es memoria de pasado y prenda del futuro dado en Jesucristo muerto y resucitado.

La gran liturgia de la renovación de la alianza en Siquem expresa de forma sugestiva cómo la Asamblea se congrega bajo la iniciativa de Dios a través de su servidor. "Josué reunió a todas las tribus de Israel en Siquem, llamó a los ancianos de Israel, a sus jefes, jueces y escribas que se situaron en presencia de Dios.» (Jos 24, 1-28) La Asamblea es el pueblo convocado por Dios. Los responsables de las tribus, pues, se situaron ante Dios, es decir, ante el que los había convocado. De ahí que la liturgia comience por la escucha de aquel que los llama y convoca. Dios narra y hace memoria de cómo formó, liberó y condujo a las tribus hasta el día de hoy, hasta el preciso momento en que se halla reunida la Asamblea. Él ha sido fiel. Se unió por amor a los antepasados y ha cumplido su palabra. Como lo había prometido se hallan ya en posesión de la tierra prometida. Por tanto, el pueblo ha de decidir a quien quiere servir. Si optan por servir a Dios, han de abandonar los dioses familiares y los ídolos de las naciones. Los convocados deciden servir a Dios y sellan la alianza. El pueblo nace de la convocación y la alianza. La Asamblea de las tribus se cierra con estas palabras tan significativas: «Josué dijo a todo el pueblo: "Mirad, esta piedra será testigo contra nosotros, pues ha oído todas las palabras que Yahvé ha hablado con nosotros; ella será testigo contra vosotros para que no reneguéis de vuestro Dios"». Y Josué despidió al pueblo cada uno a su heredad.» (Jos 24, 27-28) Es un nuevo comienzo para el pueblo.

En el horizonte del reino de Dios, anunciado y realizado por Jesús, la convocación de los pobres y excluidos es determinante. Un día fue invitado

3 Sacramentum caritatis 14 
a comer. Al final de la comida le dice a su anfitrión: «Cuando des una comida o una cena, no llames a tus amigos, ni a tus hermanos, ni a tus parientes, ni a tus vecinos ricos; no sea que ellos te inviten a su vez, y tengas ya tu recompensa. Cuando des un banquete, llama a los pobres, a los lisiados, a los cojos, a los ciegos; y serás dichoso, porque no te pueden corresponder, pues se te recompensará en la resurrección de los justos». (Lc 14, 12-24) Uno de los comensales, tocado por estas palabras, exclama: «¡Dichoso el que pueda comer en el Reino de Dios!» Jesús, como respuesta, contó la parábola de los invitados que se niegan a acudir a la gran fiesta, a la cena, que había preparado el Señor de la casa. Entonces éste envía a su siervo a los caminos y encrucijadas para convocar a «los pobres, a los lisiados, a los cojos, a los ciegos». Así se muestra la iniciativa del Señor. De hecho, Jesús llamó a los discípulos y los reunió en el cenáculo para darles a comer su cuerpo y su sangre, la sangre de la nueva alianza. La comunidad eucarística es la comunidad de los convocados, de los que han aceptado la llamada del Siervo, esto es, del Hijo venido en la condición de siervo.

La liturgia celeste, tal como se evoca en el libro del Apocalipsis, nos orienta en la misma dirección. Tras describir la alegría de los rescatados por el triunfo de Cristo, se le dice al vidente de Patmos: «Escribe: dichosos los invitados al banquete de bodas del Cordero». (Ap 19, 9) El misterio eucarístico es anticipo de la liturgia celeste. La comunidad de los creyentes es convocada para celebrar el memorial de la Pascua, de la muerte y exaltación del Cordero inmolado. El sacramento no sólo es memoria del pasado, es también prenda del futuro. Por ello en la liturgia, antes de la comunión con el cuerpo y la sangre del Cordero, se evocan las palabras del libro del Apocalipsis. «He aquí el Cordero de Dios que quita el pecado del mundo. Dichosos los invitados a la cena del Señor».

La comunidad eucarística, por tanto, ha de expresar ante el mundo que se reúne en respuesta a una invitación de Dios. Es una asamblea de convocados. El obscurecimiento de esta verdad luminosa hace que muchos vivan la Eucaristía como una mera práctica religiosa individual o como una devoción intimista; y son muchos, por desgracia, que viven la Eucaristía como el cumplimiento de un precepto que obliga bajo pecado. Cuando falta el sentido de la convocación de Dios, la celebración resulta repetitiva y aburrida, pues se pierde el sentido del diálogo con el Señor y de pertenencia al pueblo de la alianza. El Señor invita a compartir la misma mesa, el pan y la sangre de la alianza, a formar el pueblo de los ciudadanos del cielo. Tratemos ahora de precisar algunos rasgos de la vocación de la asamblea eucarística en el mundo y para el mundo. 


\section{Llamados a vivir desde el don}

La Eucaristía nos convoca, ante todo, a vivir desde el don. En ella celebra la Iglesia el culmen de la auto-donación de Dios en su Hijo. En efecto, «la Iglesia puede celebrar y adorar el misterio de Cristo presente en la Eucaristía precisamente porque el mismo Cristo se ha entregado antes a ella en el sacrificio de la Cruz. La posibilidad que tiene la Iglesia de "hacer" la Eucaristía tiene su raíz en la donación que Cristo le ha hecho de sí mismo4». La Iglesia recibe activamente en la fe el don pascual en la medida que acepta entrar en la dinámica del don de cara a Dios y al mundo.

Israel había puesto en duda que Dios pudiera prepararle una mesa en el desierto (cf Sal 78, 18), no había aprendido a vivir todavía del don de Dios. Reclamaba garantías y seguridades. Los profetas anunciaron el festín mesiánico que Dios preparaba para todos los pueblos (cf Is 25, 6s). Este festín mesiánico se celebra sacramentalmente en el misterio de la fe. La Eucaristía es el banquete del Reino.

En la sinagoga de Cafarnaún, los judíos, que habían comido pan hasta saciarse y habían pretendido proclamarle rey, le piden un signo de su identidad. Moisés les había dado en el desierto el maná. Y él, ¿qué signo hacía? Jesús les respondió: «En verdad, en verdad os digo: "No fue Moisés quien os dio el pan del cielo; es mi Padre el que os da el verdadero pan del cielo; porque el pan de Dios es el que baja del cielo y da la vida al mundo"». (Jn 6, 32-33)

El sacramento del amor celebra el don que el Padre hace de su Hijo único (cf. Jn 3, 16), así como la donación que éste hace de su cuerpo y sangre para la vida del mundo. Los que participan del misterio eucarístico, por tanto, están llamados a vivir desde el don. Llamada que comporta una actitud de profunda gratitud, humildad y entrega gozosa a un tiempo. El reconocimiento, la alabanza y la acción de gracias brotan de manera espontánea en quien vive desde el don. Puesto que todo es gracia, no puede gloriarse en sus obras; se mantiene en la humildad, en la dependencia de aquel que le hace vivir. Por otra parte, desde el más profundo agradecimiento se entrega de manera incondicional a la fuente de su vida y existencia. La persona que vive desde el don no se plantea la existencia en términos de hacer o de ley, sino en la dinámica de la reciprocidad del amor, de la donación reciproca. Y es esta relación de amor con el Tú, que toma la iniciativa de darse y consumar la alianza, el terreno abonado para las vocaciones personales dentro del pueblo de los

\footnotetext{
4 Sacramentum caritatis 14
} 
convocados. La vocación del amor, en que la persona se entrega de manera incondicional y total a la persona de Cristo, encuentra de ordinario su fuente en la adoración eucarística. El déficit de vocaciones revela el déficit de adoración, de acogida de la donación del Señor, en el que nos invita a entrar.

La Eucaristía como sacramento de la alianza nos introduce en la misma perspectiva. Dios, en la alianza, se compromete con el pueblo a ser su Dios, y espera aquél que se comprometa a ser su pueblo. Así lo expresa la fórmula de la alianza: "yo seré su Dios y ellos serán mi pueblo.» La iniciativa es de Dios. Él liberó, eligió y convocó al pueblo para la alianza. La donación reciproca es el dinamismo que sustenta el pacto de amor. Cuando falta esta dinámica, la Ley se degrada en pura norma, deja de ser don. Es lo que tantas veces ocurre a lo largo de la historia.

Vivir desde el don es, por otra parte, mucho más exigente que hacerlo desde la norma, pues supone darse sin reservas a Dios y a su designio de salvación. En la alianza, Dios espera que el pueblo dé un paso adelante y se ponga entre sus manos. Es entrar en la dinámica de la acción de gracias $^{5}$ y de la obediencia. En la cena pascual Jesús bendice y da gracias sobre el pan y el vino, pues el Padre lleva en su sangre la alianza con la humanidad a su término. En este marco se inscribe su sacrificio existencial, su obediencia desde el inicio de su vida. «Por eso, al entrar en este mundo, dice: "Sacrificio y oblación no quisiste; pero me has formado un cuerpo. Holocaustos y sacrificios por el pecado no te agradaron. Entonces dije: ¡He aquí que vengo - pues de mí está escrito en el rollo del libro - a hacer, oh Dios, tu voluntad!" Dice primero: Sacrificios y oblaciones y holocaustos por el pecado no los quisiste ni te agradaron - cosas todas ofrecidas conforme a la Ley - entonces - añade -: he aquí que vengo a hacer tu voluntad. Abroga lo primero para establecer el segundo. $Y$ en virtud de esta voluntad somos santificados, merced a la oblación de una vez para siempre del cuerpo de Jesucristo.» (Heb 10, 5-10)

La experiencia de vivir desde el don, lleva en última instancia a descubrir el camino de la obediencia y de la entrega hasta el final, a ponerse de manera incondicional al servicio del designio de Dios, según su beneplácito. Así, en última instancia, se ponen las bases de la vocación personal en el pueblo de los convocados.

Vivir desde el don es consentir, por otra parte, ser don para los demás. La

${ }^{5}$ ¡Qué diferencia tan grande existe entre la acción de gracias de Cristo y la acción de gracias del alma pagana! Jesús da gracias en el momento de ir a la muerte, pues sabe que ha llegado el momento del cumplimiento del designio salvador. El alma pagana da gracias cuando le van bien las cosas, cuando Dios se ha puesto a su servicio. ¡Qué difícil que nazca en este contexto la verdadera vocación! 


\section{"HACED ESTO EN MEMORIA MIA", ANTONIO BRAVO}

pro-existencia del Hijo, el ser para los demás, tiene su fundamento en la comunión con el amor del Padre. La pro-existencia del discípulo tiene su origen en la comunión con el amor del Hijo amando a los suyos hasta el extremo (cf. Jn 13, 1). La reciprocidad con Dios funda la reciprocidad con los hermanos y hermanas de camino. Penetrado por la dinámica del don, el comensal eucarístico toma conciencia de ser dado con el cuerpo y la sangre de Cristo en favor de los demás. La participación en la Eucaristía imprime a la existencia de la comunidad y de cada uno de sus miembros la lógica profunda del don a Dios y a los hermanos. La alianza con Dios conlleva desarrollar una verdadera relación de amor con los hermanos. La Eucaristía es comunión con Dios y con los hermanos.

Jesús, consciente de ser un don del Padre para la humanidad, no dudó en despojarse de su vida en favor de la humanidad. Pero no experimentó que el despojo de su vida fuese una exigencia impuesta desde fuera: nacía del amor, la libertad y la confianza filial. «El Padre me ama porque doy mi vida, para recobrarla de nuevo. Nadie me la quita; yo la doy voluntariamente. Tengo poder para darla y poder para recobrarla de nuevo: esa es la orden que he recibido de mi Padre.» (Jn 10, 17-18) Vivir desde el don es asumir plenamente la vocación filial, tal como se inaugura en el Bautismo y se alimenta de forma incesante en la Eucaristía. «Sed, pues, imitadores de Dios, como hijos queridos, y vivid en el amor como Cristo os amó y se entregó por nosotros como oblación y víctima de suave aroma.» (Ef 5, 1-2) Entrar en esta dinámica del don es obra, sin duda alguna, del Espíritu. Él nos injerta en el movimiento del amor que brota del Padre y culmina en la entrega libre y voluntaria del Hijo. Necesitamos, por tanto, desarrollar en la comunidad cristiana una clara conciencia de lo que incluye la actualización sacramental del don de Jesucristo. Celebrar correctamente la Eucaristía lleva consigo tomar conciencia de que somos en Cristo don los unos para los otros, que como comunidad eucarística somos don también para el mundo. Con Cristo nos damos a los demás y en él recibimos a los demás como ayuda para el camino ${ }^{6}$.

\footnotetext{
6 He aquí como san Agustín explicaba a los catecúmenos recién bautizados la relación entre la Eucaristía y su pertenencia a la Iglesia, cuerpo de Cristo: «Si queréis entender lo que es el Cuerpo de Cristo, escuchad al Apóstol; ved lo que les dice a los fieles: Vosotros sois el Cuerpo de Cristo y sus miembros. (1Cor 12, 27) $\mathrm{Si}$, pues, vosotros sois el Cuerpo y los miembros de Cristo, lo que está sobre la santa mesa es un símbolo (mysterium vestrum in mensa Dominica positum est: mysterium vestrum accipitis) de vosotros mismos, y lo que recibís es vuestro mismo emblema. Vosotros mismos lo refrendáis así al responder: Amén. Se os dice: He aquí el Cuerpo de Cristo, y vosotros contestáis: Amén; así es. Sed, pues miembros de Cristo para responder con verdad: Amén.» (Sermón 272)
} 
La vivencia del don, por tanto, es fuente de nuevas relaciones con Dios y con los hermanos. La Eucaristía es fuente de una nueva moralidad, pero ha de evitarse por todos los medios una lectura moralista del sacramento del amor fraterno. El don de Dios nos introduce en la solidaridad y donación misma del Hijo en favor del mundo, pero desde la comunión del amor. En esta perspectiva, escribe Benedicto XVI: «Esta referencia al valor moral del culto espiritual no se ha de interpretar en clave moralista. Es ante todo el gozoso descubrimiento del dinamismo del amor en el corazón que acoge el don del Señor, se abandona a él y encuentra la verdadera libertad. La transformación moral que comporta el nuevo culto instituido por Cristo, es una tensión y un deseo cordial de corresponder al amor del Señor con todo el propio ser, no obstante la conciencia de la propia fragilidad ${ }^{7} »$.

\section{Llamados a ser lo que recibimos}

El mandato dado por Jesús a los discípulos: «haced esto en memoria mía» implica, además de la reiteración sacramental, el dinamismo de una existencia que llega a ser toda ella eucarística. Es una llamada a transformarnos en lo que recibimos. Así lo postula la tensión escatológica del misterio de nuestra fe. Juan Pablo II lo expresa de una forma magistral: "Anunciar la muerte del Señor "hasta que venga" (1Co 11, 26), comporta para los que participan en la Eucaristía el compromiso de transformar su vida, para que toda ella llegue a ser en cierto modo "eucarística".

Precisamente este fruto de transfiguración de la existencia y el compromiso de transformar el mundo según el Evangelio, hacen resplandecer la tensión escatológica de la celebración eucarística y de toda la vida cristiana: "iVen, Señor Jesús!" » $(A p 22,20)^{8}$. Esta transformación de la propia vida, para que toda ella llegue a ser eucarística, es una llamada apremiante a vivir la existencia desde la lógica del amor de Cristo 9 . Cuesta entenderlo, pues el camino del amor conlleva el paso por el pesebre y la cruz. La humildad y

\footnotetext{
7 Sacramentum caritatis 82

8 EDE 20

9 Pablo expresa así la lógica del amor en el que debe entrar quien conoce en la fe, y no según la carne, a Jesucristo, tal como lo celebra el sacramento del amor. «Porque el amor de Cristo nos apremia al pensar que, si uno murió por todos, todos por tanto murieron. Y murió por todos, para que ya no vivan para sí los que viven, sino para aquel que murió y resucitó por ellos. Así que, en adelante, ya no conocemos a nadie según la carne. $\mathrm{Y}$ si conocimos a Cristo según la carne, ya no le conocemos así.» (2Cor 5, 14-16)
} 


\section{"HACED ESTO EN MEMORIA MIA", ANTONIO BRAVO}

pobreza de Belén, la humillación y sufrimiento de la cruz, hacen posible el don de la Eucaristía. Pues bien, el que come el cuerpo y bebe la sangre de Cristo, si lo hace con fe viva, será introducido en esa corriente de amor. La mística del sacramento se basa en el abajamiento del Hijo de Dios ${ }^{10}$.

Los Padres de la Iglesia han insistido en la necesidad de llegar a ser lo que recibimos. La persona auténticamente eucarística no se limita a participar en un rito, se deja asimilar en el cuerpo de Aquel que se entrega a él. San León Magno lo expresa con encantadora sencillez: «La participación del cuerpo y de la sangre de Cristo no hace otra cosa sino convertirnos en lo que recibimos: y seamos portadores en nuestro espíritu y en nuestra carne, de aquel en quien y con quien hemos sido muertos, sepultados y resucitados ${ }^{11} . »$

Para entrar en este dinamismo pascual del sacramento del amor, los miembros del pueblo de Dios han de ahondar el misterio de Cristo en la oración. De otra forma se corre el riesgo de quedar a un nivel ritual o simplemente moral ${ }^{12}$. El Concilio Vaticano II, en el decreto sobre la vida y el ministerio de la vida de los presbíteros, insiste sobre este punto con palabras incisivas. «Esta caridad pastoral fluye sobre todo del Sacrificio Eucarístico, que se manifiesta por ello como centro y raíz de toda la vida del presbítero, de suerte que lo que se efectúa en el altar lo procure reproducir en sí el alma del sacerdote. Esto no puede conseguirse si los mismos sacerdotes no penetran cada vez más íntimamente, por la oración, en el misterio de Cristo ${ }^{13}$.»

El divorcio, que tanto lamentamos, entre la Eucaristía y la vida cotidiana, se debe, en gran medida, a una falta de inteligencia del misterio del Cristo total, tal como se celebra en el sacramento de la fe. Comentando el texto de la Vid y de los sarmientos, san Agustín enseña: «Este misterio del Cristo total, de la vid y los sarmientos, de la cabeza y el cuerpo, del esposo

10 «La Eucaristía nos adentra en el acto oblativo de Jesús. No recibimos solamente de modo pasivo el Logos encarnado, sino que nos implicamos en la dinámica de su entrega. La imagen de las nupcias entre Dios e Israel se hace realidad de un modo antes inconcebible: lo que antes era estar frente a Dios, se transforma ahora en unión por la participación en la entrega de Jesús, en su cuerpo y su sangre. La "mística" del Sacramento, que se basa en el abajamiento de Dios hacia nosotros, tiene otra dimensión de gran alcance y que lleva mucho más alto de lo que cualquier elevación mística del hombre podría alcanzar» Deus caritas est 13).

11 Sermón 12

12 «En el "culto" mismo, en la comunión eucarística, está incluido a la vez el ser amados y el amar a los otros. Una Eucaristía que no comporte un ejercicio práctico del amor es fragmentaria en sí misma.» (Deus caritas est 14)

13 PO 14 
y de la esposa, se hace presente en el pan y en el vino de la Eucaristía. Porque sufrió por nosotros, encomendó a nuestra veneración su cuerpo y sangre en este sacramento. Por otra parte, nosotros mismos hemos venido a ser su cuerpo y por su misericordia recibimos de él lo que somos. (Nam et nos corpus ipsius facti sumus, et per misericordiam ipsius, quod accipimus, nos sumus). Habéis recibido un ser nuevo... Luego os habéis acercado al agua santa, habéis sido penetrados de ella y habéis venido a ser como una pasta que ha cocido el calor del Espíritu Santo, y así es como habéis llegado a ser pan sagrado. Ved ahí lo que habéis recibido. Así como veis la unidad, en lo que se ha realizado en vosotros, así también sed una misma cosa, amándoos, conservando una misma fe, una misma esperanza, una caridad indivisible... Así vosotros, después de haber pasado por tantos ayunos, por tantos trabajos, por humillación y dolores profundos, habéis entrado en algún modo a formar, en nombre de Cristo, parte del cáliz divino, y allí estáis con nosotros, puesto que comemos y bebemos esto juntamente, y juntos recibimos la vida ${ }^{14}$ ». Dicho con palabras de Benedicto XVI: «En verdad, la vocación de cada uno de nosotros consiste en ser, junto con Jesús, pan partido para la vida del mundo15».

Quien acepta dejarse transformar en lo que recibe, se compromete en la transformación del mundo, pues es designio del Padre que todo sea finalizado o recapitulado en Cristo (cf. Ef 1, 10). La tensión escatológica de la Eucaristía no significa huida o evasión del mundo, sino llamada a transformar la realidad, a preparar «el material del reino de los cielos». El Espíritu libera a todos «para que, con la abnegación propia y el empleo de todas las energías terrenas en pro de la vida, se proyecten hacia las realidades futuras, cuando la propia humanidad se convertirán en oblación acepta a Dios.» Y añade el Concilio a continuación: «El Señor dejó a los suyos prenda de tal esperanza y alimento para el camino en aquel sacramento de la fe en el que los elementos de la naturaleza, cultivados por el hombre, se convierten en el cuerpo y sangre gloriosos con la cena de la comunión fraterna y la degustación del banquete celestial16». Por tanto, la comunión sacramental con Cristo sería parcial si no incluyera el compromiso por transformar el mundo y sus estructuras al servicio de la

\footnotetext{
14 Sermón de san Agustín. Denis, n 6.

15 Sacramentum caritatis 88 .

16 GS 38. Juan Pablo II hizo hincapié en este mismo sentido: «Una consecuencia significativa de la tensión escatológica propia de la Eucaristía es que da impulso a nuestro camino histórico, poniendo una semilla de viva esperanza en la dedicación cotidiana de cada uno a sus propias tareas.» (EdE 20)
} 


\section{"HACED ESTO EN MEMORIA MIA", ANTONIO BRAVO}

dignidad del hombre. «La Eucaristía, a través de la puesta en práctica de este compromiso, transforma en vida lo que ella significa en la celebración ${ }^{17}$ ».

\section{Llamados al servicio}

En el cenáculo, Jesús se presenta como «maestro de comunión y servicio ${ }^{18}$ ». Él está en medio de los discípulos como el que sirve, como el último de los esclavos. Es su manera original de afirmar su comunión con el Padre y su solidaridad con los suyos. «El Hijo del hombre no ha venido a ser servido, sino a servir y a dar su vida como rescate por muchos.» (Mc $10,45)$ Este servicio lo lleva a cabo Jesús de forma simbólica y real en el lavatorio de los pies (Jn 13, 1-20).

El evangelista Lucas, después de narrar la institución de la Eucaristía y de anunciar la traición de Judas, relata un hecho sorprendente. Los participantes en el banquete pascual siguen comportándose según lo criterios de la cultura imperante, de los grandes de este mundo. «Entre ellos hubo también un altercado sobre quién de ellos parecía ser el mayor. El les dijo: "Los reyes de las naciones las dominan como señores absolutos, y los que ejercen el poder sobre ellas se hacen llamar Bienhechores; pero no así vosotros, sino que el mayor entre vosotros sea como el más joven y el que gobierna como el que sirve. Porque, ¿quién es mayor, el que está a la mesa o el que sirve? ¿No es el que está a la mesa? Pues yo estoy en medio de vosotros como el que sirve"» (LC 22,

\footnotetext{
17 Sacramentum caritatis 89

18 «Muchos son los problemas que oscurecen el horizonte de nuestro tiempo.
} Baste pensar en la urgencia de trabajar por la paz, de poner premisas sólidas de justicia y solidaridad en las relaciones entre los pueblos, de defender la vida humana desde su concepción hasta su término natural. Y ¿qué decir, además, de las tantas contradicciones de un mundo "globalizado", donde los más débiles, los más pequeños y los más pobres parecen tener bien poco que esperar? En este mundo es donde tiene que brillar la esperanza cristiana. También por eso el Señor ha querido quedarse con nosotros en la Eucaristía, grabando en esta presencia sacrificial y convival la promesa de una humanidad renovada por su amor. Es significativo que el Evangelio de Juan, allí donde los Sinópticos narran la institución de la Eucaristía, propone, ilustrando así su sentido profundo, el relato del "lavatorio de los pies", en el cual Jesús se hace maestro de comunión y servicio (cf. Jn 13, 120). El apóstol Pablo, por su parte, califica como "indigno" de una comunidad cristiana que se participe en la Cena del Señor, si se hace en un contexto de división e indiferencia hacia los pobres (Cf. 1 Co 11, 17.22.27.34)» (EdE 20). 
24-27). El Maestro recuerda a los suyos que no pueden servir como lo hacen los maestros de la ley, como jefes. Han de lavarse los pies mutuamente, servirse con humildad, sin buscar honores o prestigio. «Si yo, el Señor y el Maestro, os he lavado los pies, también vosotros debéis lavaros los pies unos a otros.» (Jn 13,14) Esto supone que el amor mismo de Cristo se despliegue en la existencia del discípulo. El sacramento inyecta, una y otra vez, este amor en el corazón de quien entra en comunión con él, haciéndole partícipe de su gozo en el servicio. Por eso añade Jesús: «No es más el siervo que su amo, ni el enviado más que el que le envía. Sabiendo esto seréis dichosos si lo cumplís» (v. 17) El signo de que el amor del Maestro actúa en el discípulo es la alegría en el servicio. Pablo podía alegrarse en medio de los sufrimientos, pues se sabía en comunión con Cristo entregado por nosotros, como lo celebramos en la Eucaristía. Es significativo que después de presentar el camino del Siervo, de la encarnación, muerte y exaltación, escriba a los filipenses: «Y aun cuando mi sangre fuera derramada como libación sobre el sacrificio y la ofrenda de vuestra fe, me alegraría y congratularía con vosotros. De igual manera también vosotros alegraos y congratulaos conmigo.» (Fil 2, 17-18)

El sacramento de la comunión, vivido en la fe, por tanto, hace posible que la Iglesia, cuerpo de Cristo en la historia, sirva a la humanidad con las actitudes del Siervo pobre y humilde. Esto es importante, pues ella está llamada a actualizar el amor de Dios por el hombre, pero no a la manera de los grandes de este mundo, los cuales se hacen llamar bienhechores, que es una forma de buscar los primeros puestos. La vocación del pueblo de la alianza es la libertad para el servicio gratuito, discreto y humilde. «Para ser libres nos libertó Cristo... Porque, hermanos, habéis sido llamados a la libertad; sólo que no toméis de esa libertad pretexto para la carne; antes al contrario, servíos (haceos esclavos) por amor los unos a los otros.» (Gal 5, 1.13) La Eucaristía pone así los fundamentos de una novedosa antropología. La plena realización del hombre en Cristo está en hacerse el siervo de los demás por amor. La Eucaristía es un modo nuevo de entender y vivir la existencia cotidiana. En la cultura de la autoafirmación frente a Dios y a los demás, el sacramento de la fe traza un nuevo camino de realización personal y comunitaria. La verdad del hombre nuevo se revela plenamente en el don eucarístico. La libertad del amor se acrecienta con el servicio pobre y humilde, con la participación y comunión con Cristo entregado por nosotros.

La comunidad eucarística, por otra parte, sabe que sólo el Espíritu puede introducirla y mantenerla en esta dinámica. El hombre viejo también quiere servir, pero desde el poder, autoafirmación y dominio. En la plegaria eucarística, el presidente invoca la venida del Espíritu para que transforme 


\section{"HACED ESTO EN MEMORIA MIA", ANTONIO BRAVO}

el pan y el vino en el cuerpo y la sangre de Cristo; también lo invoca para que haga en Cristo de la asamblea una víctima viva para alabanza de la gloria de Dios Padre. En las diferentes versiones de la Plegaria V, se pide al Padre de misericordia derrame sobre la comunidad «el Espíritu del Amor, el Espíritu de tu Hijo», para que siendo una en la fe y el amor, desarrolle las actitudes mismas de Cristo con relación a los más necesitados. "Danos entrañas de misericordia ante toda miseria humana, inspíranos el gesto y la palabra oportuna frente al hermano solo y desamparado, ayúdanos a mostrarnos disponibles ante quien se siente explotado y deprimido.»

La celebración de la Eucaristía es fragmentaria, dice Benedicto XVI, si no desarrolla en los comensales las mismas entrañas de amor de Cristo por los más pobres y desvalidos. La comunión con él lleva a los invitados al banquete del amor a hacerse un pan con él para la vida del mundo. Comunión y servicio se postulan mutuamente. Así se explica que Pablo denuncie las asambleas eucarísticas que no recrean la unidad y sirven para humillar a los pobres. De la entraña misma del sacramento brota la llamada a vivir la comunión y a servir con alegría y humildad a los más débiles y vulnerables.

La comunidad de Corinto se hallaba atravesada por profundas divisiones, entre otras cosas porque los entendidos y pretendidamente libres no respetaban a los débiles en la fe: los escandalizaban con su manera de proceder ante lo sacrificado a los ídolos. Pablo recordaba estos criterios para recrear la unidad en torno a los más débiles: «La ciencia hincha, el amor en cambio edifica;» no hay más que un Dios, el Padre, y un solo Señor, Jesucristo; y añadía: «Y por tu conocimiento se pierde el débil: ¡el hermano por quien murió Cristo! Y pecando así contra vuestros hermanos, hiriendo su conciencia, que es débil, pecáis contra Cristo.» (1Cor 8, 1-12). Por otra parte, recordaba a fuertes y débiles la necesidad de huir de la idolatría y de permanecer en la unidad, pues en el Cristo eucarístico formaban todos un solo pan. "Os hablo como a prudentes. Juzgad vosotros lo que digo. La copa de bendición que bendecimos ¿no es acaso comunión con la sangre de Cristo? Y el pan que partimos ¿no es comunión con el cuerpo de Cristo? Porque aun siendo muchos, un solo pan y un solo cuerpo somos, pues todos participamos de un solo pan.» (1Cor 10,15-17)

El sacramento, conviene insistir en esta llamada intrínseca al misterio, exige de los invitados al banquete de la alianza una real solidaridad con los más indigentes. No se los puede menospreciar ni humillar, antes bien hay que darles un lugar de privilegio. La comunión en el Cuerpo de Cristo, que es la Iglesia, ha de llevarse a cabo a través de los más débiles y pobres. «Dios ha formado el cuerpo dando más honor a los miembros que carecían 
de él, para que no hubiera división alguna en el cuerpo, sino que todos los miembros se preocuparon lo mismo los unos de los otros» (Cfr 1Cor 12, 24-25). El Apóstol denuncia con énfasis la conducta de quienes en el seno de la celebración eucarística menosprecian a los pobres ${ }^{19}$. «Y al dar estas disposiciones, no os alabo, porque vuestras reuniones son más para mal que para bien. Pues, ante todo, oigo que, al reuniros en la asamblea, hay entre vosotros divisiones, y lo creo en parte. Desde luego, tiene que haber entre vosotros también disensiones, para que se ponga de manifiesto quiénes son de probada virtud entre vosotros. Cuando os reunís, pues, en común, eso ya no es comer la Cena del Señor; porque cada uno come primero su propia cena, y mientras uno pasa hambre, otro se embriaga. ¿No tenéis casas para comer y beber? ¿O es que despreciáis a la Iglesia de Dios y avergonzáis a los que no tienen?» Y el Apóstol concluye, después de comunicar la tradición recibida del Señor: «Por tanto, quien coma el pan o beba la copa del Señor indignamente, será reo del Cuerpo y de la Sangre del Señor. Examínese, pues, cada cual, y coma así el pan y beba de la copa. Pues quien come y bebe sin discernir el Cuerpo, come y bebe su propio castigo» (1Cor 11, 17-22.27-29). El sacramento de la alianza impulsa a establecer relaciones de justicia y solidaridad con los pobres, con aquellos con los que el Señor quiso identificarse de manera particular. Trabajar por la justicia y la solidaridad, por la reconciliación de los pueblos, por establecer la fraternidad es la forma de recibir activamente el don de Dios. La comunión con Cristo se expresa así en la solidaridad con los débiles en la fe y con los más indigentes.

El encuentro y comunión con Cristo en el sacramento de la fe no es algo abstracto o intimista. Es una llamada a caminar en el Espíritu (cf. Gal 5, 25) y, por ello, a trabajar para que los excluidos sean puestos en el centro de las preocupaciones de nuestras comunidades y de la sociedad. La mística oblativa de la Eucaristía, enraizada en el misterio de la encarnación, ha de desplegarse en el amor y servicio concreto al hermano indigente; y esto tanto a nivel de las personas como de los pueblos y culturas. Una celebración correcta misterio pascual hace que abracemos con Cristo a todo hombre y mujer, en espacial a los excluidos y malditos a los ojos de los hombres.

\footnotetext{
19 En esta dinámica eucarística se ilumina lo que el propio Pablo dice de cómo el ministro del Evangelio ha de situarse al servicio de la comunidad: «Porque pienso, a los apóstoles, Dios nos ha asignado el último lugar» (1Cor 4, 9).
} 


\section{Llamados a la misión}

La celebración del sacramento de la fe es en ella misma misionera. La asamblea eucarística proclama la muerte del Señor hasta que venga. San Pablo, al transmitir la tradición del Señor, añade: «Cada vez que coméis este pan y bebéis esta copa, anunciáis la muerte del Señor, hasta que venga.» (1Cor 11, 26) Este anuncio de la muerte del Señor hasta su vuelta en gloria, es el fundamento de la misión, del anuncio de la Buena Nueva de Dios a la humanidad entera. De la Eucaristía, por tanto, brota la llamada apremiante a la misión, a salir a las plazas públicas y a las encrucijadas de los caminos para darles a conocer el amor de Dios y convocar a los excluidos al banquete de bodas del Cordero. Ya lo hemos dicho, la cena pascual es la culminación de toda la actividad evangelizadora de Jesús. Su invitación a la conversión y a la fe ante la cercanía del reino de Dios desemboca en la celebración del banquete del Reino. Al dar a comer su cuerpo y beber la sangre de la nueva alianza, Jesús anunciaba de forma sorprendente el camino de la cruz como el camino de la liberación y de la plena realización de los oráculos de los profetas. El camino de la fraternidad estaba abierto. Los discípulos saben desde ahora donde pueden reconocer al Mesías de los pobres, en la fracción del pan. La esperanza está alumbrada, pues el Señor permanece con nosotros hasta el final de los tiempos. Con el cuerpo y la sangre de Cristo, la comunidad apostólica recibe el Espíritu que le permite permanecer fiel a la nueva alianza.

«No podemos acercarnos a la Mesa eucarística sin dejarnos llevar por ese movimiento de la misión que, partiendo del corazón mismo de Dios, tiende a llegar a todos los hombres. Así pues, el impulso misionero es parte constitutiva de la forma eucarística de la vida cristiana ${ }^{20}$ ». La Eucaristía celebra y recuerda la vocación y la razón de ser de la Iglesia: la evangelización de los pueblos y culturas, de los pobres y oprimidos. Pablo VI formulaba en términos emotivos esta verdad: «Evangelizar constituye, en efecto, la dicha y vocación propia de la Iglesia, su identidad más profunda. Ella existe para evangelizar ${ }^{21} »$. La identidad y la vocación de la

\footnotetext{
20 Sacramentum caritatis 84

21 EN 14. Unas líneas más arriba, el Papa evocaba la misión de Jesús y la del apóstol Pablo. La evangelización supone estar siempre de camino hacia los que están lejos. "La Iglesia lo sabe. Ella tiene viva conciencia de que las palabras del Salvador: "Es preciso que anuncie también el reino de Dios en otras ciudades", se aplican con toda verdad a ella misma. Y por su parte ella añade de buen grado, siguiendo a San Pablo: "Porque, si evangelizo, no es para mí motivo de gloria, sino que se me impone como necesidad. ¡Ay de mí, si no evangelizara!" ».
} 
Iglesia se diluyen cuando deja de ser misionera, cuando deja de salir a los caminos para anunciar la muerte de Cristo hasta que vuelva. Si se cierra sobre ella misma en una actitud de autodefensa, a pesar de lo que ciertas corrientes eclesiásticas y espiritualistas propugnan, pierde la verdadera identidad, el impulso vocacional y la razón de ser en el mundo.

Necesitamos volver una y otra vez a la Eucaristía, fuente y culmen de la misión. De la celebración del amor de Dios nace la misión y a la celebración de ese amor conduce la misión. El Concilio Vaticano II enseña: «la Liturgia es la cumbre a la cual tiende la actividad de la Iglesia y al mismo tiempo la fuente de donde mana toda su fuerza ${ }^{22} »$. Donde la Eucaristía se celebra de forma correcta, nunca faltarán las vocaciones misioneras. ¿Cómo guardarnos para nosotros el don de Dios? ¿Cómo no compartir con los demás el reconocimiento de Cristo en la fracción del pan? Los discípulos de Emaús se retiraban tristes, pero cuando reconocen a Jesús en la fracción del pan, vuelven a la Comunidad y salen en misión. Los discípulos no podían callar lo que habían visto, oído y palpado del Verbo hecho carne. Y esto es lo que sucede también a los discípulos de todos los tiempos que viven un auténtico encuentro con Jesús en el sacramento del amor: salen a los caminos para anunciar, con sencillez, audacia y lágrimas, como el apóstol, la buena nueva de Dios: Jesucristo muerto por nuestros pecados y resucitado para nuestra justificación (cf. Rom 4, 25).

El misterio eucarístico, por otra parte, expresa con todo realismo el contenido y la pedagogía de la misión. «La Eucaristía es Cristo que se nos entrega, edificándonos continuamente como su cuerpo ${ }^{23}$ », y de esta forma nos incorpora a su hora, esto es, a su ofrenda al Padre en favor de la humanidad entera. Pablo escribía a la comunidad de Corinto, que se hallaba inmersa en luchas intestinas de poder y prestigio: «yo, hermanos, cuando fui a vosotros, no fui con el prestigio de la palabra o de la sabiduría a anunciaros el misterio de Dios, pues no quise saber entre vosotros sino a Jesucristo, y éste crucificado. Y me presenté ante vosotros débil, tímido y tembloroso. Y mi palabra y mi predicación no tuvieron nada de los persuasivos discursos de la sabiduría, sino que fueron una demostración del Espíritu y del poder para que vuestra fe se fundase, no en sabiduría de hombres, sino en el poder de Dios.» (1Cor 2, 1-5)

En la celebración eucarística, por otra parte, se halla el ámbito más apropiado para inculturar el evangelio de Dios. En efecto, quien se deja penetrar por el dinamismo del amor desarrolla una nueva antropología y

22 SC 10

23 Sacramentum caritatis 14 


\section{"HACED ESTO EN MEMORIA MIA", ANTONIO BRAVO}

hace realidad la Buena Nueva en su propia cultura. En una palabra, la evangelización de la cultura y de las culturas, así como la inculturación del Evangelio de la gracia, dependen en gran medida de la celebración del misterio eucarístico.

Como conclusión de estas reflexiones, quiero insistir en la importancia de vivir el sacramento de la Eucaristía como el lugar privilegiado del reconocimiento de la persona viva de Cristo. Es capital para las vocaciones en la Iglesia. Así lo enseña el encuentro del Resucitado con los discípulos de Emaús. Si este reconocimiento es auténtico, las personas y comunidades no pueden quedar indiferentes. Se instaurará necesariamente un diálogo con él, que se prolongará en lo concreto de la existencia. En ese diálogo, el Señor da a conocer y gustar su palabra, caldea nuestros corazones y nos muestra el camino a seguir de acuerdo con el plan de Dios sobre cada uno de nosotros. Y en el discípulo brota de forma espontánea la pregunta: ¿Qué quieres de mí, qué mandas? Y también la respuesta inicial de toda vocación: Heme aquí, envíame. Ha comenzado el diálogo de la vocación, que se ira concretando de forma progresiva en la historia. Unos serán llamados, en su condición de ministros de la nueva alianza, a representar a Cristo presidiendo y encabezando la marcha de la asamblea eucarística. Otras personas se sentirán llamadas al don total de sus vidas al Señor y a los hombres, en la vida consagrada. Otras, al don reciproco de una vez para siempre en el matrimonio. El sacramento del amor, en definitiva, es el espacio privilegiado donde brota y se desarrolla la vocación del pueblo de Dios y de cada uno de sus miembros. La Eucaristía nos capacita a vivir desde el don y a ser don para los demás. ¿No es este el dinamismo profundo de toda vocación en el pueblo de los convocados? Pero esto supone una actitud de profundo silencio, de oración y adoración para reconocer una presencia y entregarse sin reservas a Aquel que nos entrega su cuerpo y su sangre para que vivamos de él, por él y para él. «El que come mi carne y bebe mi sangre, permanece en mí, y yo en él. Lo mismo que el Padre, que vive, me ha enviado y yo vivo por el Padre, también el que me coma vivirá por mí» $(J n$ 6, 56-57) 
